\title{
Improving Business Processes Efficiency and Quality by Using BPMS
}

\author{
Igor Fiodorov $^{1 \text { [0000-0003-2335-0452] }}$, Alexander Sotnikov ${ }^{2}$ [0000-0003-2985-3704], \\ Yury Telnov ${ }^{1 \text { [0000-0002-2983-8232] }}$, Nixon Muganda Ochara ${ }^{3 \text { [0000-0001-5736-7901] }}$ \\ ${ }^{1}$ Plekhanov Russian University of Economics, 36 Stremyanny lane, Moscow, 115998, Russia \\ Igor.Fiodorov@mail.ru, YTelnov@rea.ru \\ 2 Joint Supercomputer Center of the Russian Academy of Sciences, \\ 32a, Leninsky Prospect, Moscow, 119334, Russia \\ ASotnikovajscc.ru \\ ${ }^{3}$ The University of Venda, University Rd, Thohoyandou, 0950, South Africa \\ Nixon. Muganda@gmail.com
}

\begin{abstract}
The tasks of economic growth is a priority for the BRICS countries. It implies the rise of labor productivity. However, one should not expect that this growth will be achieved through the expanded use of information technologies. Labor productivity is not determined by the level of technology development or the equipment used. A high degree of automation does not guarantee increase in productivity. The organization of production depends on both technical and governance factors. The latter $t$ involves coordinated implementation of various processes. It can be concluded that enterprises in the non-industrial sector and public administration should pay more attention to their business processes. The use of BPMS - process oriented IT systems can help these enterprises to increase their labor productivity, and the states to ensure sustainable economic growth.
\end{abstract}

Keywords : BPMS; process oriented IT systems; virtual conveyor.

\section{Introduction}

Organizations that pose ambitious development challenges must choose a strategy: either extensive, by means of quantitative increase of production factors, or intensive, based on using increasingly more efficient production means. We use to think that the change from the extensive development strategy to the intensive one depends solely on automation. However, automation reduces the cost of individual operations, whereas the main problem is in coordination sphere - cross-boundary collaboration of company units. Publications frequently call the switch to process-based management to be an important factor of innovative development. Unfortunately process management in non-industrial sphere goes on hesitantly, the main causes often being the complexity of business processes, high cost of modeling, questionable results of im-

Proceedings of the 10th International Scientific and Practical Conference named after A. I. Kitov "Information Technologies and Mathematical Methods in Economics and Management (IT\&MM-2020)", October 15-16, 2020, Moscow, Russia

(c) (i) 2021 Copyright for this paper by its authors.

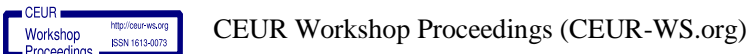


plementation. IT implementation, if we consider technological benefits, produces a local effect and rarely increases efficiency and labor productivity of the whole enterprise, so that economic benefits are achieved only when they are supported by effective organizational practices.

According to IDC in 2016 Russia was among the top countries for IT expenditure [1]. However, this did not serve the growth of labor productivity of Russian companies. The study fulfilled by McKinsey Global Institute (MGI) [2] analyzes the growth of labor productivity in Russia within the last 10 years, compares performance indicators in five main sectors of the Russian economy to the similar industries in US.

It is noted that, over the past decade, the average value of productivity in Russia has grown from $18 \%$ (compared to the US level in 1999) up to $26 \%$ in 2007 , which provided 2/3 of the growth in GDP per capita. The economic growth in Russia was ensured by extensive factors: thanks to the utilization of free production capacities and the influx of foreign labor. The authors note that the low level of labor productivity of Russian enterprises in almost all areas of activity does not exceed 10-30\% of the level of labor productivity in the United States, which does not ensure either the sustainable development of our economic system, or its competitiveness in the global economy, or an increase in the real quality of life. most people.

Interesting conclusions can be drawn if we compare the performance by sectors of the economy, given in the MGI report (see Figure 1.1) [2]. We are surprised to discover that the non-productive banking sector turns out to be by far the most prosperous. Labor productivity in it is only $23 \%$ of that of the United States, while the average value of the indicator for all industries is $26 \%$, although it is obvious that IT costs in this sector are among the highest. For comparison, labor productivity in manufacturing sectors, for example, in the steel industry, is significantly higher than average and amounts to $33 \%$. The financial sector Russian remains to be one of the most automated and resourced [3]. During last decades IT investments in banking have been much higher than in other market segments. It can be concluded from the above that it is a mistake to think that productivity depends only on the level of automation and technology development. High level of automation does not guarantee high productivity, the latter is the result of good labor organization. This confirms N. Carr's observation that the key to company's long-term market success are the effective business processes but not the high-tech solutions [4].

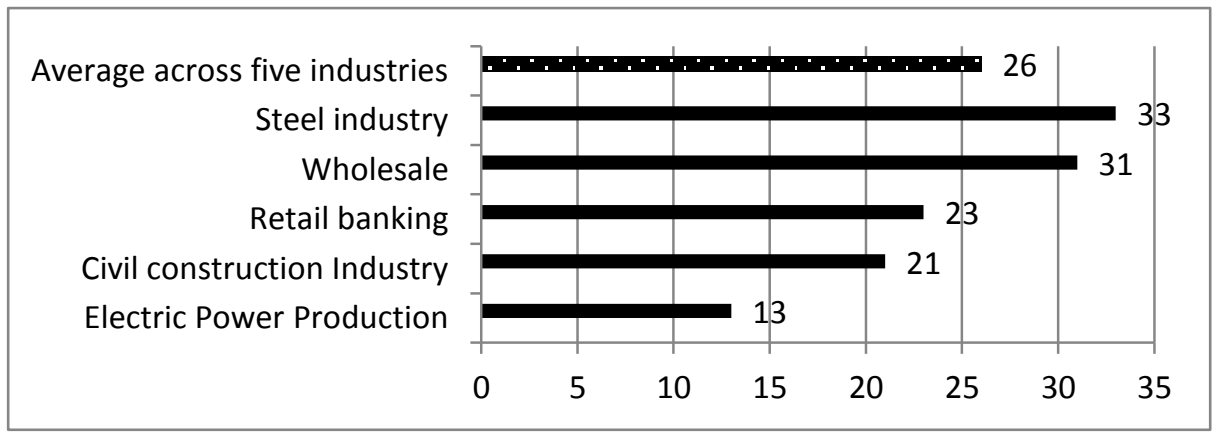

Fig. 1. The Productivity in Russia (compared to US) by sectors of economy [2] 
It is interesting to compare the findings in the MGI report on labor productivity in Russia [2] with the results of a similar study by the same company: «US Productivity Growth 1995-2000, Understanding the Contribution of Information» [2], which analyzes IT contribution to the growth of labor productivity in six sectors of US economics [5]. The study performed in USA demonstrated correlation of IT investments with labor productivity in retail and wholesale sectors, heavy impact in semiconductor and computer production sectors and weak influence in the retail banking sphere and hotel industry. It can be seen that both in Russia and in USA IT contribution is best visible in the same sectors - in the production industry, where the processes are welladjusted, the effect is considerable, while in banking and insurance sectors, where process are less formalized, IT influence is less obvious.

It can be assumed that the obtained result reflects the peculiarity of the Russian market, however, the research by MGI in the United States - «US Productivity Growth 1995-2000, Understanding the Contribution of Information Technology » investigating the impact of information technology in different sectors of economy (see Table 1), refute this hypothesis [5]. It can be noted that both in Russia and in the United States productivity is higher in manufacturing industries where organizational and economic relations between the participants are well formalized, while in industries where these relations are less formalized, the impact of IT on labor productivity growth is weaker.

Table 1. The impact of information technology in different sectors of economy [5]

\begin{tabular}{|c|c|c|}
\hline & \multicolumn{2}{|c|}{ The Contribution of Information Technology } \\
\hline & Is perceptible & Is insignificant \\
\hline \multirow{4}{*}{$\begin{array}{c}\text { Market } \\
\text { segmants }\end{array}$} & $\begin{array}{c}\text { Electronic components man- } \\
\text { ufacturing }\end{array}$ & Insurance services \\
\cline { 2 - 3 } & Telecommunications & Depository institutions \\
\cline { 2 - 3 } & Wholesale & Investment and pension funds \\
\cline { 2 - 3 } & Retail & Consulting and business services \\
\cline { 2 - 3 } & Dealing with securities & Media business \\
\hline
\end{tabular}

The purpose of this work is to address the changing of paradigms of using state-ofthe-art IT, to find new representations that can help non-manufacturing companies increase operational efficiency. We will try to prove that the implementation of business process management (BPM) systems will be accompanied by significant organizational changes, shifting of company management paradigm, focusing on business operations, use of conveyor- production methods.

\section{The reason for low productivity}

What is the reason for low labor productivity in a non-manufacturing sphere? Let us take the banking sector as an example. M. Hammer and D. Champy noticed that not products, but effective processes of their creation and development, guaranty companies long-term and sustainable success [5]. Most of manufacturing companies pay close attention to their technological processes, which insure the growth of effi- 
ciency [6]. On the contrary, the non-production sector does not too decisively move to the process management, does not regularly improve its business processes. Companies are constantly looking for ways to reduce costs and, in terms of economic criteria, optimize their organizational structure, cut staff, do not notice that the transition to process management will not only improve efficiency and reduce costs, but will also lead to an increase in the quality of customer service, risks reduction [7].

As it is noted [8], the banking services sphere is characterized by the absence of strict procedures for personnel actions. In contrast to the industry, where managers keep a wary eye on the observance of process requirements and punish for any deviations from the technological process, in the financial sphere only the most general description of personnel actions is considered to be admissible, which leads to high variability of processes and, as a result, to low efficiency and client satisfaction.

The financial sphere traditionally goes by hiring top-ranked professionals, who know individual operations. However the end-to-end processes binding up individuals are drawn very general, showing what should be done, without explaining how it must be done. Unfortunately the specialists are apt to vary their actions basing on their individual experience gained in companies with different processes or level of automation. As a result, two employees performing same operation can do it differently. Due to variability the end-to-end processes remain uncoordinated. Thus, the employers' strategy of hiring top-ranked professionals does not guarantee the increase in efficiency. Therefore reducing business processes variability is the primary objective.

\section{The influence of IT on the enterprise labor productivity}

Nowadays researchers are skeptical about the role of information technologies in the improvement of business performance. First, the assessment of IT influence on the increase of labor productivity is ambiguous, so only a limited number of implementations ensure positive effect for organizations [9], [7]. Second, there is a high risk of failure during the implementation of corporate information systems [10]. At the same time, it is obvious that qualitative changes in the company and enterprise management technology are impossible without using up-to-date IT systems. However, local IT improvement does not guarantee maximum efficiency of the overall organizational system. Automation of individual process operations is not capable of solving the global task of increasing labor efficiency, productivity and quality and may even prove to be harmful for the entire organization. R. Solow, Nobel Prize winner in Economics, has defined the so-called "productivity paradox", which postulates that is not possible to conclusively demonstrate the connection between IT investments and measurable results of organization productivity increase [11]. E. Brynjolfsson, L. Hitt and S. Yang studied the correlation between IT investments and organizational and human capital assets [12]. They showed that a modern effective enterprise should be regarded as a set of complementary assets, so that the increase of one promotes profitability growth of the others. Thus, a combination of IT and certain organizational practices creates a greater value than each of them does individually. P. Milgrom and 
J. Roberts's studies confirmed interconnection between investments into information technologies and organizational practices [13].

The research by P. Milgrom and D. Roberts confirmes the close relationship between investments in information technology and organizational practices [14]. They believe that the main condition for the effective development of an enterprise is the consistent creation and development of complementary practices, including IT technologies, organizational management, and human capital.

It can be concluded that labor productivity growth for the company is ensured only by those IT implementations, which are accompanied by heavy changes in the company organizational practices. Thus there is a contradiction between the necessity of ensuring economic growth and the capability of technologies, on the basis of introduction of modern information systems, to ensure required economy growth rate.

According to G. Smith and P. Fingar [15], enterprise reengineering did not offer a real solution to economic problems, commercialized, ceased to be attractive for business. It is now associated with austerity and side effects of organizational structure reduction. Reengineering consultants often substitute the transformation of business processes with the introduction of IT, for example, expensive enterprise resource planning (ERP) information systems, in which the so-called. best practice processes are at the code level and can only be slightly modified through customization.

\section{A process as a conveyor}

The invention of a conveyor increases labor productivity in industrial manufacturing significantly. The conveyor implies clear division of labor and observance of operation sequence. All conveyor operations are clearly specified and detailed, deviation from the process is not allowed. It can be said that the conveyor unify, regulate and synchronize the participants.

When we talk about a non-manufacturing industry, we should consider a business process as a virtual conveyor that consolidates the work of all the participants in order to achieve the required result. Within a business process a work is broken down into individual well-formalized operations, each is performed by the participant in its respective role. The deviations from the procedure are not allowed. A business process is labor organization regulating and synchronizing performance sequence with the purpose of attaining the highest possible labor productivity and performance quality.

\section{Process-based and functional IT}

Let us look at the classification of IT systems by the use of business processes. Functionally-oriented information systems automate the set of functions, while the execution order of operations is not specified since it is controlled by the operator, who plays the active role, while the system plays the auxiliary role - provides necessary services. If some of execution scenarios were not completely identified during the development phases, the operator at the execution time can implement it. As a result, the user has to keep in mind all the process scenarios, so the work with such system requires user training. On the other hand, when developing a functionallyoriented information system it is important to define all the functions, but it is not 
necessary to define all execution scenarios. That is why many process models identify only frequently used scenarios and miss rarely used ones.

An IT system is called a process aware, if a business process model was used for its design [16]. For example, implementation of most enterprise resource planning (ERP) systems starts with process modeling, but can we say that those ERP systems were created to implement the process-based approach? In these circumstances modeling is performed in order to draw up the requirements. The IT system remains functionally-oriented.

A process-oriented system coordinates interaction of participants with each other and with other information systems in such a way that the tasks including information and documents are transferred between the participants (people and systems) in accordance with the formalized procedural rules. Such systems play an active guiding role, defining the order and the time of operation execution, while people play a subordinate role, their participation being reduced to fulfilling the tasks. This class includes numerous workflow systems. Some process-oriented information systems contain hard-coded process logics. They are created by programmers, so changing interaction procedural rules can be a labor-consuming challenge requiring coding. For example legacy workflow required coding in proprietary dialects of business process modeling languages. Other process-oriented systems are model-driven, they are developed in a graphical notation and provide businesses with the capability of understanding their internal procedures. The model is designed in the terms of the application domain, so the designer is protected from programming difficulties.

\section{Business process management systems}

The Gartner defines business process management [17] as (a) the information technology of model-oriented development of process-oriented enterprise automation systems with closed cycle of modeling, execution, analysis and modification of a process model; (b) the management concept of continuous improvement of business processes aimed at increasing efficiency, productivity and quality of those processes. Business process management systems belong to two classes: process-oriented and model-driven. They are intended to organize effective interaction between all the process stakeholders, enable to monitor fulfillment of tasks with respect to both time and quality in accordance with predetermined criteria, help the process owner win through the results of deviations emerging during process execution [18]. The effect of interaction coordination makes itself evident in the fact that procedures becomes shorter, the execution becomes less costly, while quality increases. The processoriented systems are aimed at getting synergetic effect from coordinated activities of company business units. We can say that the process-oriented systems are created to implement the process-based approach.

\section{The factors of BPMS economic impact}

The economic impact of BPM system may be classified as direct, indirect and exploitative (see Table 2). The direct impact is manifested in the reduction of process execution costs and product quality improvement, while the indirect impact is defined 
by associated factors, like user loyalty, risks, productivity. The exploitative impact reveal in costs of development and services. Let have a short look at these impact factors. The execution cost depends on the number of operations to be performed, time spend for each operation and labor fee of a personnel. BPM system implementation usually starts with process reengineering to eliminate the redundant and obsolete operations. The execution time can be decreased by the use of self-contained tasks that provide each participant the resources it needs to supply an output [19]. These tasks are well defined thus can be performed by an employee with a less qualification and smaller remuneration. The product quality depends on the variability of the process and the assignment of responsibility [20]. The self-contained task encompass an instruction on how to perform it, leaving only one way of execution and in this way decrease the variability. The elimination of unnecessary operations makes easier to find an employee in charge of the result. The exploitative impact includes costs of design, debugging and maintenance. Due to a visual model oriented development the design tine becomes shorter, most of the bugs can be found in the early development phase. Business process executable model requires less coding compared to traditional development while a round trip development makes easier the adaption of a model to changes of customer requirements. According to Gartner assessments [21] 67\% of all BPM projects were successfully completed in less than 4 months, including $50 \%$ in less than one month, all the projects had ROI above $10 \%$, including $78 \%$ with ROI above $15 \%$.

Process management is considered to be the main factor of a client-oriented strategy of company development. For the client it means simplification of all the procedures and for the owner - business excellence due to optimization of operations and compliance with all regulations. Unfortunately the evaluation of this factors requires the metrics which are not always known to BPM implementation partner shows the results of an empirical study of the factors of BPM system economic impact.

Table 2. The factors of BPM economic impact (in \%)

\begin{tabular}{|c|c|c|}
\hline & Factors & Impact \\
\hline \multirow{6}{*}{ 芯 } & Elimination of unnecessary function & 10 \\
\hline & Reduction of execution cost & 10 \\
\hline & Wage bill reduction & 20 \\
\hline & $\begin{array}{l}\text { Release of human resources due to the } \\
\text { switch to process-based management }\end{array}$ & 05 \\
\hline & $\begin{array}{l}\text { Loss reduction due to the decrease of } \\
\text { reject rate }\end{array}$ & 15 \\
\hline & Increase of service quality & - \\
\hline \multirow{3}{*}{ 家 } & Increase of client loyalty & - \\
\hline & Reduction of risks & - \\
\hline & Increase of labor productivity & 20 \\
\hline \multirow{4}{*}{ 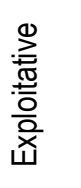 } & Speed and cost of development & 50 \\
\hline & The cost of debugging & 30 \\
\hline & Speed and cost maintenance & 25 \\
\hline & Versioning of a process model & 30 \\
\hline
\end{tabular}




\section{An example of BPM in Sberbank}

Banks were the first to use the terms a «credit factory» and a «loan conveyor» understanding by this a conveyor for the processing of repetitive tasks implemented through the instrumentality of a business process management system. In the Sberbank of Russia the «credit factory» is a centralized automated crediting technology, which comprises a complex of IT systems and bank employees performing the procedures of decision-making, that covers the entire process from the moment of client entering the bank office to get the loan and up to the moment of a loan granting [22]. The technology includes the automated procedure of checking and assessing the borrowers by the data obtained from internal and external sources, centralized decision-making on loan granting. This solution has been implemented in 701 Sberbank's loan sales points in Moscow.

The implementation of the «credit factory» allowed the bank reduce the time for decisions making and decrease the number of client's visits to the bank. If earlier it took more than two days to get a decision on a loan, now it is available in less than a day. Earlier the client had to visit Sberbank at least four times (or even six-seven times if guarantees from physical persons were provided as collaterals) and after the implementation of new system the number of visits has reduced to two. Furthermore, the borrower now has to approach one desk only. The new technology has significantly changed the procedure of decision-making. With legacy "paper-based" technology some events, related to client history and important for making a decision, were not taken into account. The switch to a «paper-free» technology brought about more complex credit rules regarding the borrower's assessment, where part of them is based on statistically average data (event analysis by clients similar to this borrower), part on the information of client behavior in the past. As a result the method of borrower's paying capacity calculation has changed with an obvious effect on the reject rate regarding the issued loans.

The new mechanism has considerably increased efficiency and reduced the cost of their execution. The efficiency of credit inspectors has increased by more than 2.5 times and of risk management employees - by more than 10 times. The process has become controllable and clear, time of system response to changes has reduced.

\section{Conclusions}

We make a inference that the problems of productivity growth are not connected with the shortcomings of the IT technologies, but with their integration into the enterprise business processes. It is wrong to restrict all problems only to the shortcomings of the IT technologies, as this creates the illusion that the emergence of yet another, new IT technology miracle will suddenly change the situation qualitatively.

We conclude that the economic effect of the BPM systems is associated with the enterprise process transformation, but this concept is considered today unilaterally, as the implementation of the process approach. We assume that the enterprise process transformation is connected with a complex organizational change and presupposes the emergence of new conveyor production methods. 
The result is important for BRICS countries, that lack of labor productivity, especially in governmental sector [23]. It states that in order to improve the performance and productivity the country should pay more attention to the organization of production, rather than rely on implementation of modern IT. The widespread use of BPM systems will provide an increase in the productivity of management processes, thus guaranty sustainable development of BRICS countries.

\section{Acknowledgements}

The study is funded by RFBR and NRF according to the research project No. 19-57$60004 / 19$. The study was done within the framework of the state assignment (research topic: 065-2019-0014 (reg. no. AAAA-A19-119011590097-1). The study is funded by RFBR according to the research project No. 19-07-01137 A.

\section{References}

1. Farish R. Russia's IT Market Outlook 2017 // IDC Knowlegde Club. URL: http:// idcrussia.com/ru/events/64712-idc-knowlegde-club-russia-s-it-market-outlook2017

2. Bakatina D., Duvesar J.P., Klintsov V., Krogmann K., Remes Y., Solxhenitsyn E., Швакман И. Effective Russia: Labor Productivity productivity as a foundation for growth (in Russian), McKinsey Global Institute, -M:, http://www.mckinsey.com/insights/winning_in_emerging_markets/lean_russia_su staining_economic_growth 2009.

3. IDC. IT market in Russia (in Russian) // TADVISER. 2015. URL: www.tadviser.ru?index.php?\%D0\%9F\%DO $\%$ B5\%D1\%80\% $\% 1 \% 81 \% \mathrm{D} 0 \% \mathrm{BE}$ $\% \mathrm{D} 0 \% \mathrm{BD} \% \mathrm{D} 1 \% 8 \mathrm{~B}$

4. Carr N. Does IT Matter? Information Technology and the Corrosion of Competitive Advantage. Harvard Business Review ( Firm's secret), 2003.

5. MGI. US Productivity Growth 1995-2000, Understanding the Contribution of Information Technology, McKinsey Global Institute, 2001.

6. Telnov Y. Reengineering of business processes (in Russian). Moscow: Finance and Statistics, 2005.

7. Skripkin C. Economic efficiency of information systems in Russia (in Russian). M.: Max Press, 2014. 155 pp.

8. Frei F., Kalakota ., Leone ., Marx . Process Variation as a Determinant of Bank Performance: Evidence from the Retail Banking Study // Management Science, Vol. 45, No. 9, September 1999.

9. Lugatchev M., Skripkin C., Anan'in V., Zimin K. IT investment efficiency. Almanac of the best works // IT-Value.RU. 2014. URL: http:/it-value.postach.io/ post/effektivnost-investitsii-v-it-almanakh-luchshikh-rabot (date of access: 15.01.2015).

10. The Standish Group Report. Chaos, The Standish Group, 1995. 
11. Solow R. We'd Better Watch Out // The New York Times, No. Book Review of the Myth of the Post-Industrial Economy, 1987.

12. Brynjolfsson E., Hitt L., Yang S. Intangible Assets: Computers and Organizational Capital // Brookings Papers on Economic Activity: Macroeconomics, Vol. 2, No. 1, 2002. pp. 137-199.

13. Milgrom P., Roberts J. The Economics of Modern Manufacturing: Technology, Strategy, and Organization // The American Economic Review, Vol. 80, No. 3, 1990. pp. 511-528.

14. Milgrom P., Roberts . The Economics of Modern Manufacturing: Technology, Strategy, and Organization // The American Economic Review, Vol. 80, No. 3, 1990. pp. 511-528.

15. Smith ., Fingar . Business Process Management: The Third Wave. Meghan Kiffer, 2006. 312 pp.

16. Dumas M., van der Aalst W.M.P., ter Hofstede A.H.M.. Process-Aware Information Systems: Bridging People and Software through Process Technology. Wiley \& Sons, 2005.

17. Gartner. Business Process Management // Technology Defined IT Glossary. 2011. URL: http://www.gartner.com/it-glossary/business-process-management-bpmstandards (date of access: 2015.November.15).

18. Cherniak L. BPM: near perspectives and distant horizons // Open Systems Magazine, No. 11, 2004.

19. Galbraith J. Organisation design: An information processing view // Interfaces, Vol. 4, No. 3, 1974. pp. 28-36.

20. Shewhart W. Economic control of quality of manufactured product. -NY: D. Van Nostrand Company, 1931. $501 \mathrm{pp}$.

21. Sinur J. Justifying BPM Projects, Gartner Inc., 2004.

22. Makovskaya N. Loans. The technology case // Direct investments, Vol. 85, No. 5, 2009.

23. Institute for Applied Economic Research. Towards a Long-term Strategy for BRICS: a Proposal by the BRICS Think Tanks Council / BRICS Think Tanks Council. -Brasilia: IPEA., Brasil: , 2015. 